\title{
HYDROXYAPATITE SHEET PREPARED FROM ALPHA-TRICALCIUM PHOSPHATE BY HYDROTHERMAL METHOD
}

\author{
Giichiro Kawachi ${ }^{1}$, Hirotaka Fujimori ${ }^{2}$, Seishi Goto ${ }^{2}$, Nakamichi Yamasaki ${ }^{1}$ and Koji Ioku $^{1 *}$ \\ (*Corresponding author: ioku@mail.kankyo.tohoku.ac.jp) \\ ${ }^{1}$ Graduate School of Environmental Studies, Tohoku University, \\ Sendai, Miyagi, 980-8579, Japan \\ ${ }^{2}$ Division of Applied Medical Engineering Science, Graduate School of Medicine, Yamaguchi University, \\ Ube, Yamaguchi, 755-8611, Japan
}

Keywords: Hydroxyapatite, $\alpha$-tricalcium phosphate, hydrothermal methods, scaffold

Hydroxyapatite $\left(\mathrm{Ca}_{10}\left(\mathrm{PO}_{4}\right)_{6}(\mathrm{OH})_{2}: \mathrm{HA}\right)$ is widely used as bioceramics. In general, sintering process is indispensable to give shape to the ceramics. However, it is impossible to control the crystal face of materials surface. Using hydrothermal reactions for HA preparation, it is possible to control the crystal face and the chemical composition. The authors reported various kinds of HA materials prepared by the unique hydrothermal methods.

In the present investigation, porous HA sheet with tailored crystal surface were prepared by the hydrothermal method. The HA sheet prepared at $120{ }^{\circ} \mathrm{C}$ under the saturated vapor pressure of water for $3 \mathrm{~h}$ was composed of rod-shaped HA crystals. These crystals were about $30 \mu \mathrm{m}$ in length with aspect ratio of about 10 and they had non-stoichiometric HA composition of $\mathrm{Ca} / \mathrm{P}$ molar ratio less than 1.67. This material must be suitable as scaffold for cultured bone, for bone graft material and for drug delivery system (DDS).

(Received xxx yy, 2004; Accepted zzz ww, 2004)

\section{INTRODUCTION}

Because of excellent biocompatibility, hydroxyapatite $\left(\mathrm{Ca}_{10}\left(\mathrm{PO}_{4}\right)_{6}(\mathrm{OH})_{2}\right.$ : HA) is widely used as implant materials [1,2]. Polycrystalline $\mathrm{HA}$ with random crystal surface prepared by sintering has already been used as a bone-repairing material which can directly bond to natural bones in bony defect. In addition, HA is used as a material for chromatography column.

In general, sintering process is indispensable to give shape to the ceramics. However, it is impossible to control the crystal face of materials surface. HA has typical two crystal face ( $a$-surface and $c$-surface). Adsorption properties of HA depend on the crystal face. These areas of crystal face depend on morphology. Fig.1 shows typical HA morphology (Plate-shape and Rod-shape). In rod-shape HA, area of $a$-surface is larger than that of $c$-surface. If HA materials could have the tailored specific crystal surface, the HA materials should have the advantage of adsorptive activity.

Thus, crystal face control by controlling of crystal morphology leads to quick bone repairing and give good materials for regenerative medicine. The authors reported various kinds of HA materials, for exsample, fine single crystals, whiskers, dense or porous ceramics, sheets, spherical particles, etc., prepared by the unique hydrothermal methods [3-12]. Using hydrothermal reactions for $\mathrm{HA}$ preparation, it is possible to control the crystal face, pore structures and its chemical composition.

In the present investigation, porous HA sheet with tailored crystal surface were prepared by the hydrothermal method $[8,9,11]$. This material must be suitable as scaffold for cultured bone, for bone graft material and for drug delivery system (DDS).

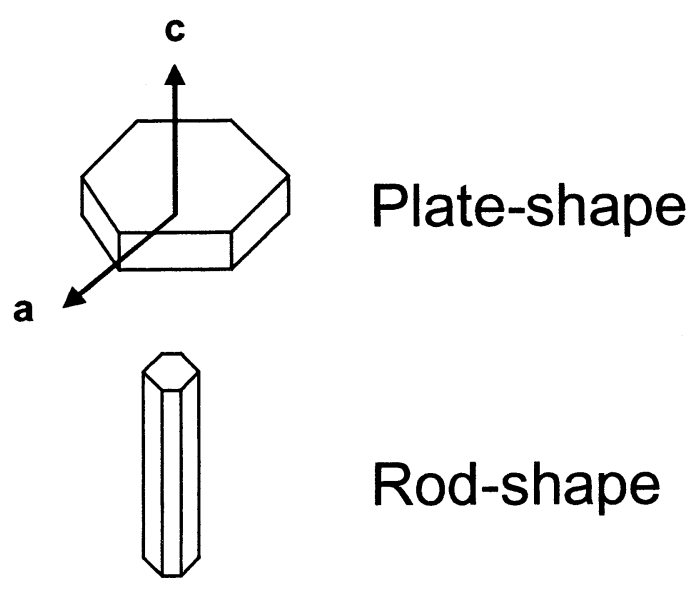

Fig. 1 Crystal morphology of HA 
Kawachi G, Fujimori H, Goto S, Yamasaki N, Ioku K MATERIALS AND METHODS

Preparation method of HA sheet was shown in Fig. 2. Commercial powders of $\alpha$-tricalcium phosphate $\left(\alpha-\mathrm{Ca}_{3}\left(\mathrm{PO}_{4}\right)_{2}: \alpha\right.$-TCP, Taihei Chemical Industrial Co., Ltd., Japan) and polyvinyl alcohol (PVA, Wako Pure Chemical Industries Ltd., Japan) were used as the starting materials. The slurry of $\alpha$-TCP with PVA was prepared by using 10 mass\% PVA solution at room temperature.

To remove bubbles, the slurry was kept under vacuum condition. Films of $\alpha$-TCP with PVA were prepared from this slurry by spin coating technique. This method is very popular technique to preparing polymer film. The glass dish was set on the turntable, and then the slurry was cast in the glass dish and twiddled. Films of $\alpha$-TCP with PVA were dried at room temperature for about $12 \mathrm{~h}$. In order to control the thickness of films, rotation speed was controlled.

The dried films were cut into circular shape of about $12 \mathrm{~mm} \varphi$. Then they were heated at $1200^{\circ} \mathrm{C}$ for 5 min in air to remove organic matter. The sample was set in autoclave and treated hydrothermally at the temperatures at 120 to $200{ }^{\circ} \mathrm{C}$, for $5 \mathrm{~h}$ under the saturated vapor pressure. The part of samples were heated at $900^{\circ} \mathrm{C}$ for $3 \mathrm{~h}$ in air for estimation of $\mathrm{Ca}$ and $\mathrm{P}$ composition of the HA prepared by hydrothermal treatment. Calcium deficient $\mathrm{HA}(\mathrm{Ca} / \mathrm{P}$ mole ratio < 1.67) was decomposed into stoichiometric $\mathrm{HA}$ $(\mathrm{Ca} / \mathrm{P}=1.67)$ and stoichiometric $\beta-\mathrm{TCP}(\mathrm{Ca} / \mathrm{P}=1.50)$. This phenomenon was used in order to determine the HA and $\beta$-TCP contents [5].

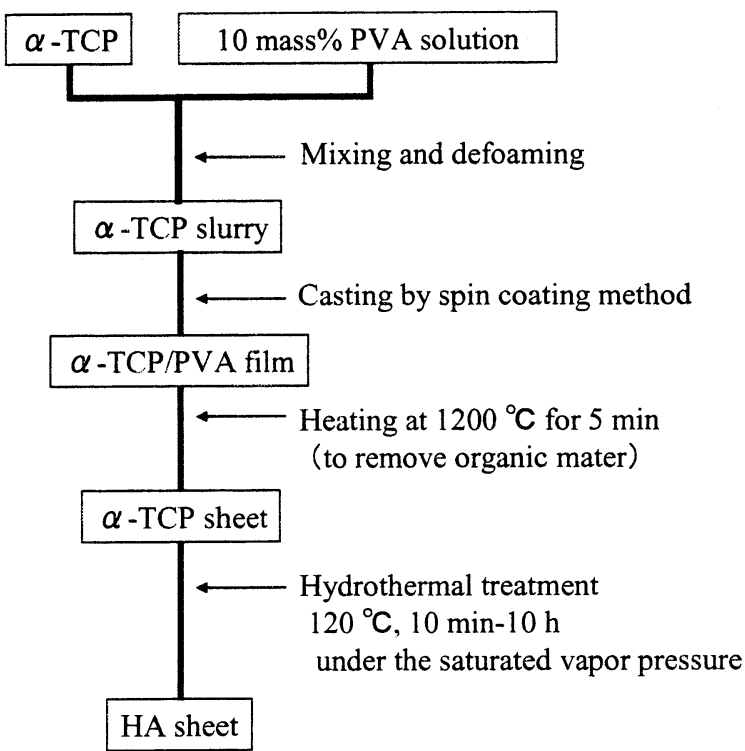

Fig. 2 Preparation method of HA sheets.
The produced phases were identified by powder X-ray diffraction with graphite-monochromatized $\mathrm{CuK} \alpha$ radiation, operating at $40 \mathrm{kV}$ and $20 \mathrm{~mA}$ (XRD; Rigaku, Geiger flex 2027, Japan). The microstructure of specimens was observed by scanning electron microscope (SEM; JEOL, JSM-T300, Japan). Pore volume and distribution of pore diameter were measured by mercury intrusion porosimetry (MIP; Carlo Elba, Porosimeter 2000, Italy). Thermal analysis and measurement (TG-DTA; Seiko Instruments Inc. TG/DTA32, Japan) were conducted up to $1200^{\circ} \mathrm{C}$ with heating rate $10{ }^{\circ} \mathrm{C} / \mathrm{min}$, and the standard material being $\alpha-\mathrm{Al}_{2} \mathrm{O}_{3}$ (Wako Pure Chemical Industries Ltd., Japan).

\section{RESULTS AND DISCUSSION}

The thickness of $\alpha$-TCP film was controlled from about $50 \mu \mathrm{m}$ to about $1 \mathrm{~mm}$ by controlling of rotation speed. The mixture film of $\alpha-$ TCP and PVA could be made into a convenient form. To remove PVA, the mixture of $\alpha$-TCP and PVA film was heated at 1200 ${ }^{\circ} \mathrm{C}$ for $5 \mathrm{~min}$ in air. The shape of sheets did not change and handling of the sample was not difficult. From $\mathrm{XRD}$, there were no phases other than $\alpha$-TCP after heating at $1200^{\circ} \mathrm{C}$.

By using hydrothermal method $[8,9,11], \alpha$-TCP was changed into HA and the sample was hardened because of hydration of $\alpha$-TCP. From X-ray diffraction, all peaks were assigned to HA [13]. So, all sheets treated hydrothermally between 120 and $200^{\circ} \mathrm{C}$ was HA (Fig. 3). Relative Intensity of (300) diffraction were higher than (112) diffraction. This results shows HA sheets consisted rod shaped HA. The area of $a$-surface was larger than that of $c$-surface in rod shape.

The HA sheet after heating at $900{ }^{\circ} \mathrm{C}$ for $3 \mathrm{~h}$ in air contained HA and $\beta$-TCP. The relative intensity of XRD lines for HA and for $\beta$-TCP was used in order to determine the HA and $\beta$-TCP contents and then the $\mathrm{Ca} / \mathrm{P}$ molar ratio of samples was estimated. The value of $\mathrm{Ca} / \mathrm{P}$ of the $\mathrm{HA}$ sheet prepared by hydrothermal treatment at $120^{\circ} \mathrm{C}$ for $3 \mathrm{~h}$ was 1.56 , that was lower than $\mathrm{Ca} / \mathrm{P}$ of stoichiometric $\mathrm{HA}(\mathrm{Ca} / \mathrm{P}=1.67)$. This results shows $\mathrm{HA}$ sheets consisted calcium deficient hydroxyapatite. The $\mathrm{Ca} / \mathrm{P}$ molar ratio of $\mathrm{HA}$ sheets were increased treating temperatures. The highest value was 1.60 (Table 1 ).

Fig. 3 shows the sheet prepared by hydrothermal treatment at $120^{\circ} \mathrm{C}$ for $5 \mathrm{~h}$ under the saturated vapor pressure. The porosity of HA sheet was about $75 \%$ and specific surface area was about $30 \mathrm{~m}^{2} / \mathrm{g}$.

$\alpha$-TCP sheet prepared by hydrothermal treatment at $120^{\circ} \mathrm{C}$ for $5 \mathrm{~h}$ was composed of rod-shaped crystals elongated along the $c$-axis by SEM observation (Fig. $5)$. The rod-shaped crystals were about $10 \mu \mathrm{m}$ in length and locked together to make micro-pores of about $10 \mathrm{~nm}$ and about few $\mu \mathrm{m}$ in size. The size of micro-pores increased gradually with the hydrothermal treatment period (Fig. 6). 


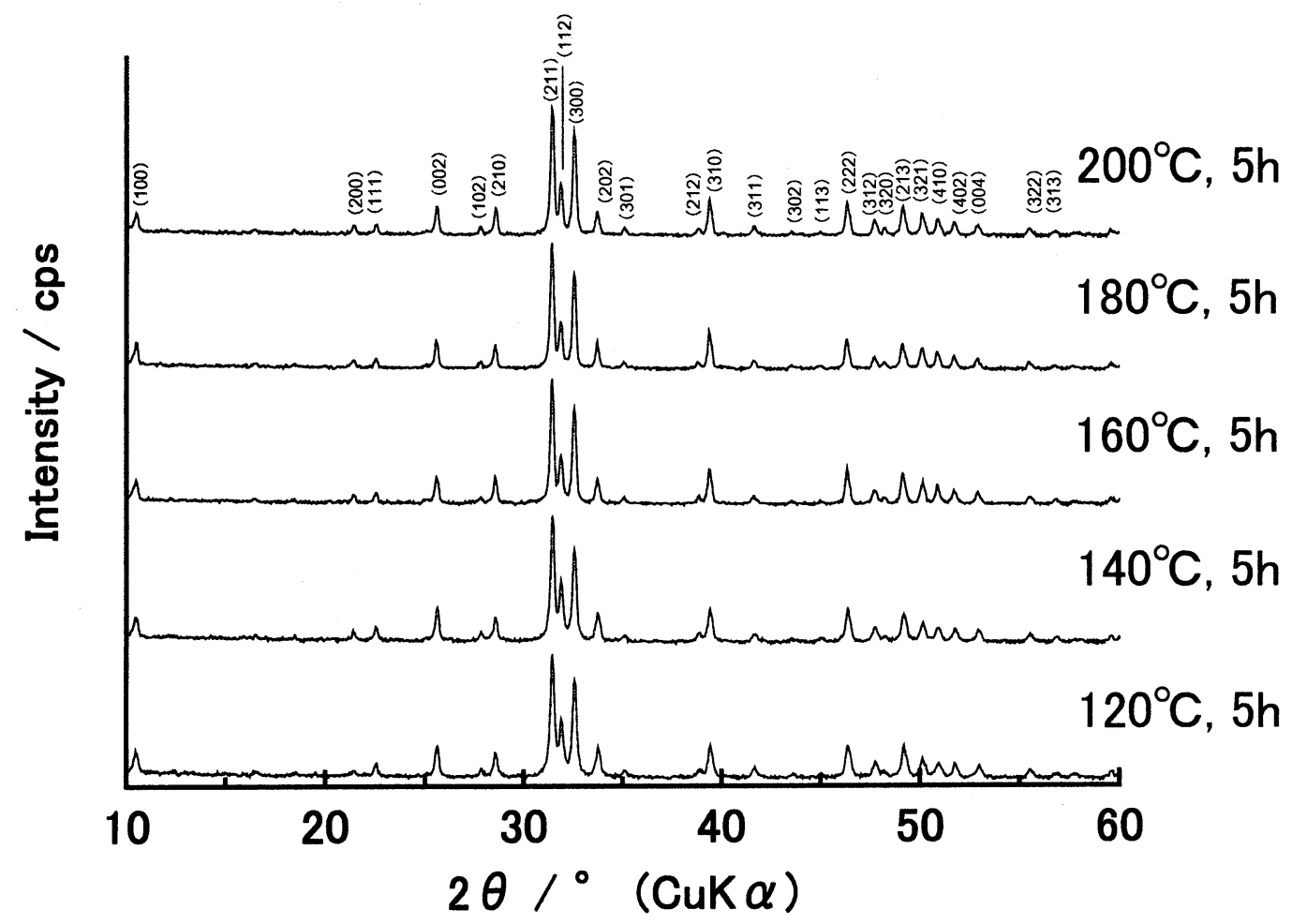

Fig. $3 \mathrm{XRD}$ patterns of HA sheets treated hydrothermally at indicating temperatures.

Table1 Relationship of hydrothermal temperatures and $\mathrm{Ca} / \mathrm{P}$ molar ratio of $\mathrm{HA}$ sheets

\begin{tabular}{cc}
\hline temperature $/{ }^{\circ} \mathrm{C}$ & $\mathrm{Ca} / \mathrm{P}$ molar ratio \\
\hline 120 & 1.56 \\
140 & 1.57 \\
160 & 1.59 \\
180 & 1.60 \\
200 & 1.59 \\
\hline
\end{tabular}

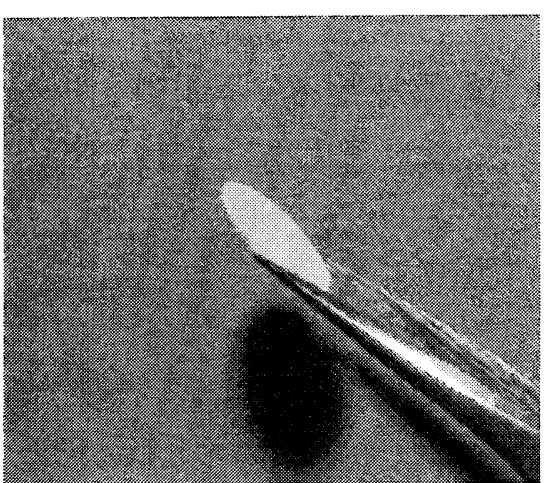

Fig. 4 HA sheet prepared by hydrothermal treatment at $120^{\circ} \mathrm{C}$ for $5 \mathrm{~h}$ under saturated vapor pressure.

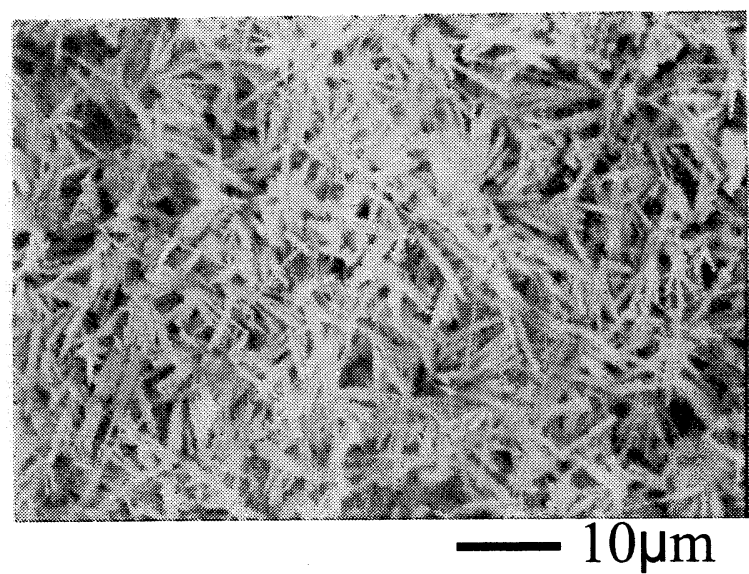

Fig. 5 SEM image of the sample prepared hydrothermally at $120^{\circ} \mathrm{C}$ for $5 \mathrm{~h}$. 


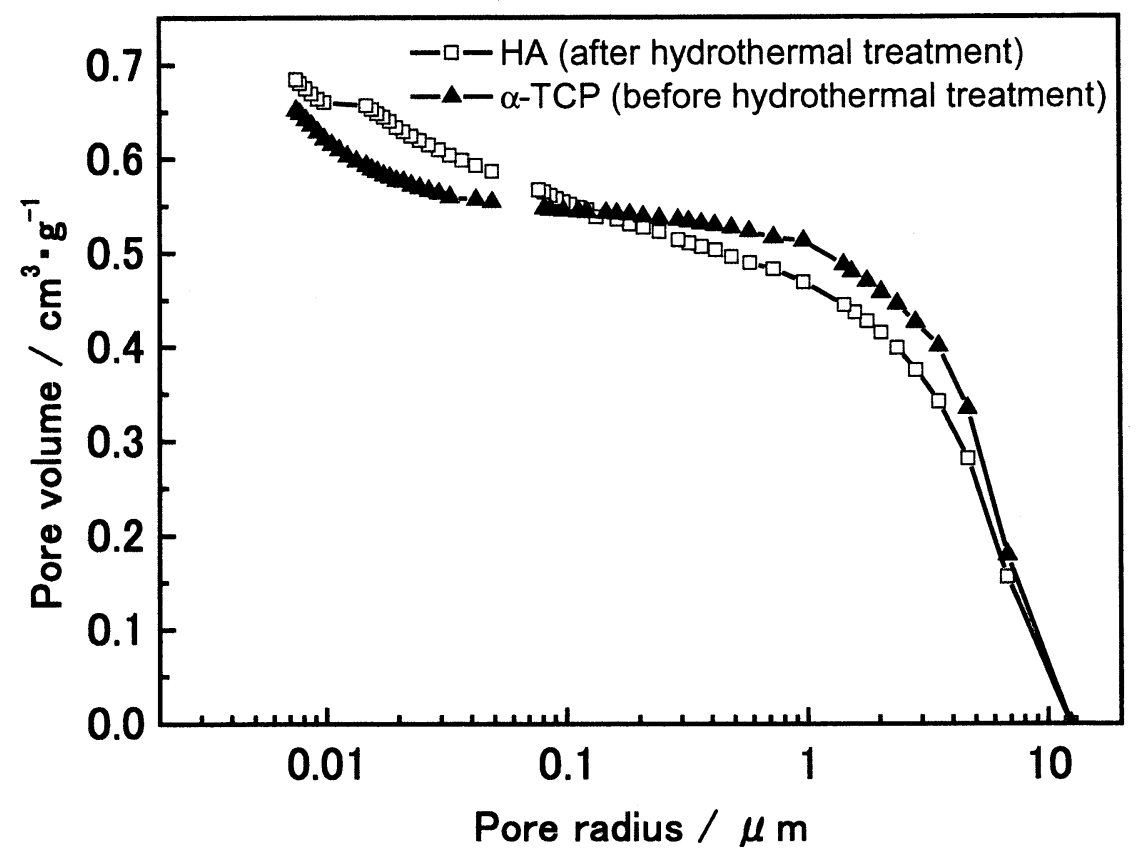

Fig. 6 Pore distribution of the sample before and after hydrothermal treatment $\left(120^{\circ} \mathrm{C}, 5 \mathrm{~h}\right)$.

\section{REFERENCES}

1. M. Jarcho: Clin. Orthop. No.157 (1981), p.259.

2. K. Ioku: J. Soc. Inorg. Mater. Japan Vol.3 (1996), p.412.

3. K. Ioku, M. Yoshimura and S. Somiya: Nippon Kagaku Kaishi (J. Chem. Soc. Japan) No.9 (1988), p. 1565.

4. K. Ioku, M. Yoshimura and S. Somiya: Bioceramics Vol. 1 (Ishiyaku EuroAmerica, Tokyo and St. Louis 1989), p. 62.

5. K. Ioku, T. Murakami, Y.Ikuma, and $M$. Yoshimura: J. Ceram. Soc. Japan Int. Edition Vol. 100 (1992), p. 1015.

6. M. Yoshimura, H. Suda, K. Okamoto and K. Ioku: J. Mater. Sci. Vol. 29 (1994), p. 3399.

7. K. Ioku, K. Yamamoto, K. Yanagisawa and N. Yamasaki: Phosphorus Res. Bull. Vol. 4 (1994), p. 65
8. K. Ioku, S. Nishimura, Y. Eguchi and S. Goto: Rev. High Pressure Sci. Technol., Vol. 7 (1998), p. 1398.

9. K. Ioku, M. Fukuhara, H. Fujimori and S. Goto: Korean J. Ceram. Vol. 5 (1999), p. 115.

10. K. Ioku, A. Oshita, H. Fujimori, S. Goto and M. Yoshimura: Trans. Mater. Res. Soc. Japan Vol. 26 (2001), p. 1243.

11. K. Ioku, H. Misumi, H. Fujimori, S. Goto and M. Yoshimura: Proc. 5th Int. Conf. Solvo-Thermal Reactions (Rutgers, The State Univ. of NJ, USA 2002), p.233.

12. K. Ioku, S. Yamauchi, H. Fujimori, S. Goto and M. Yoshimura: Solid State Ionics, Vol. 151 (2002), p. 147.

13. JCPDS \#4-432 